\title{
Crohn's Disease of the Esophagus: Dilation of Stricture and Fibrin Sealing of Fistulas
}

In a series of 35 patients with histologically confirmed Crohn's disease in the bowel, two showed involvement of the esophagus. On endoscopy, the first patient (a 24-year-old woman) was seen to have a reddish nodular swelling, and had an epithelioid-cell granuloma in the biopsy specimen. The second patient, a 27-yearold man, had been suffering from Crohn's disease for six years, and presented with dysphagia and coughing attacks caused by aspiration. Several aphthoid lesions, $2-3 \mathrm{~mm}$ in size, with red halos and a severe, nontraversable stenosis, were seen in the distal esophagus. Two fistula openings were also diagnosed (Figure 1). Repeatedly performed biopsies showed only unspecific inflammatory changes. Radiography revealed a stricture with a maximum diameter of 2.5 $\mathrm{mm}$ and a length of $3 \mathrm{~mm}$, as well as two intramural fistulas and one fistula canal leading dorsally into the mediastinum (Figure 2). In five consecutive weekly sessions, the stricture was gradually dilated up to $14 \mathrm{~mm}$, using Savary bougies. The largest fistula was closed with fibrin sealant (Tissucol/Tisseel, Immuno Company). Both of these endoscopically performed therapeutic measures proved to be primarily successful. Eighteen months later, the patient complained of coughing after drinking fluids. An esophagobronchial fistula was seen on the barium swallow (Figure 2). The patient underwent surgical treatment, and the esophagobronchial fistula was detached and closed. At present, 18 months after surgery and three years after the termination of dilation treatment, the patient has still not presented with dysphagia.

The esophagus is rarely affected by Crohn's disease. Lenaert et al. (1) found that the esophagus was involved in 15 out of 230 patients $(6 \%)$ with Crohn's disease. Fibrin sealing of anal, rectovaginal and vesicorectal fistulas has been successfully performed (2). According to the author's information, this case is the first successful closure of an esophagomediastinal fistula with fibrin sealant, although there was a recurrence 18 months later.

Similar to our procedure, Bonavina used a Savary-Gillard bougie to progressively dilate a $6 \mathrm{~mm}$ fibrotic stricture in Crohn's disease of the esophagus, and achieved a good long-term result for 20 months (3). In two cases, Eder-Pustow-bougie balloon-dilation has been used successfully (4).

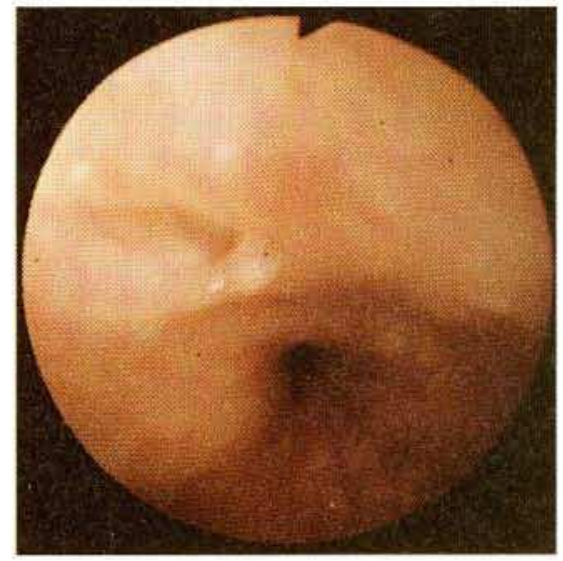

Figure 1:

Endoscopic appearance of a fistula opening in the distal third of the esophagus.

\section{G. Mathis ', G. Sutterlïtt ${ }^{\prime}, K$. Dirschmid ${ }^{3}$, M. Feuerstein ${ }^{2}$, G. Zimmermann ${ }^{4}$}

${ }^{1}$ Department of Internal Medicine and ${ }^{2}$ Department of Radiology, Hohenems General Hospital, Hohenems, Austria; ${ }^{3}$ Pathological Institute and ${ }^{4}$ Department of Surgery, LKH, Feldkirch, Austria

\section{References}

1 Lenaerts $C$, Roy CC. Vailancour $M$ et al.: High incidence of upper gastrointestinal tract involvement in children with Crohn's disease. Pediatrics 1989; 83: 777 .

2 Eimiller A, Zellmer, $R$, Neuhaus H, Paul F; Fibrin sealing of fistulae in Crohn's disease. Z. Gastroenterol. 1987; 25: 450 .

3 Bonavina L, Bettineschie F, Cecchetto A, Pomerri F: Crohn's disease of the esophagus. Dysphagia 1989; 4: 176.

4 Yanaga K, Iwamatsu M, Yukizane T, Shimiziu S: Esophageal stricture in Crohn's disease: A case report. Jpn J Surg 1986; 16: 68.

\section{Corresponding Author}

G. Mathis, M.D.

Department of Internal Medicine, Hohenems General Hospital Bahnhofstrasse 31, A-6845 Hohenems, Austria
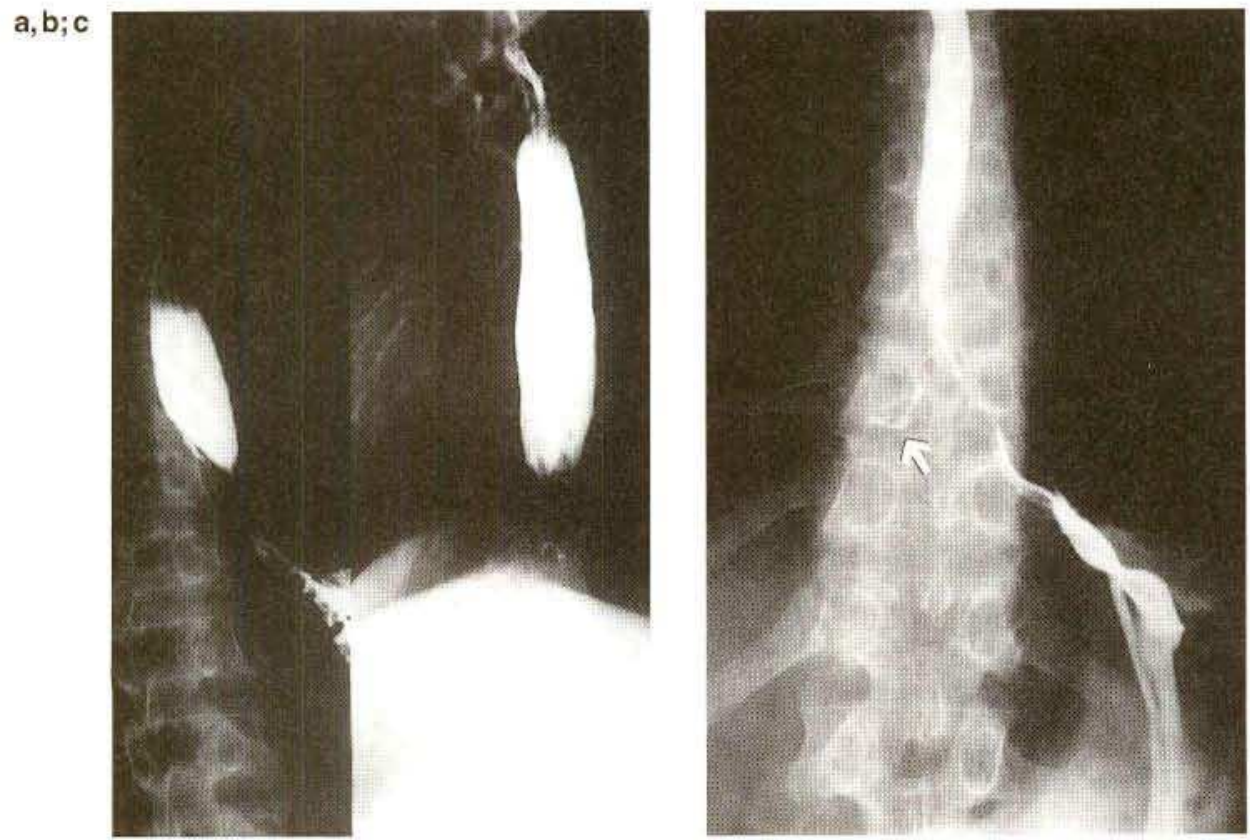

Figure 2: A high-grade stricture, $2.5 \mathrm{~mm}$ in diameter and $3 \mathrm{~mm}$ in length (a,b). Intramural sinus tracts (a), esophagomediastinal fistulas, and esophagobronchial fistulas $(\rightarrow)$. Successful bougie dilation was carried out (c). 